Supporting Information

\title{
Base-to-Base Organocatalytic Approach for One-Pot Construction of Poly(ethylene oxide)-Based Macromolecular Structures
}

\author{
Yening Xia, Ye Chen, Qilei Song, Shuangyan Hu, Junpeng Zhao*, and Guangzhao Zhang \\ Faculty of Materials Science and Engineering, South China University of Technology, Guangzhou \\ 510640, People's Republic of China
}

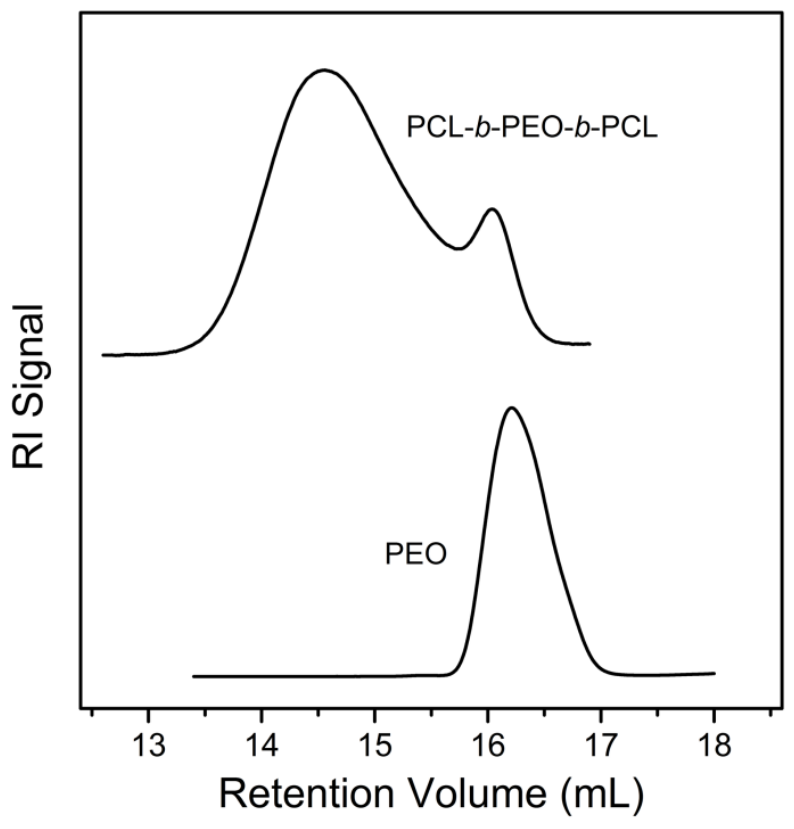

Figure S1. SEC traces (THF, $35{ }^{\circ} \mathrm{C}$ ) of a PEO precursor (EO1 in Table 1) and product yielded by addition of CL directly into the "living" PEO solution without the "catalyst switch" step (reaction time of $\mathrm{CL}=1 \mathrm{~h}$ ), the ratio of $\left[t-\mathrm{BuP}_{4}\right]_{0} /[\mathrm{OH}]_{0}$ being 0.1 . 


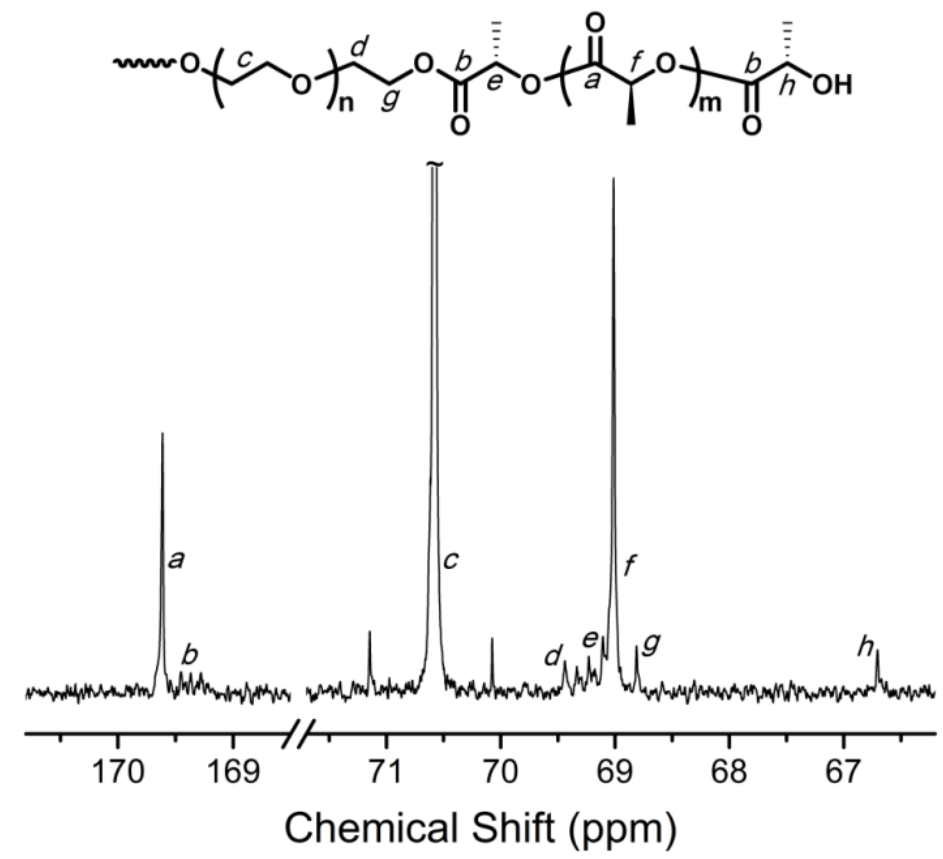

Figure S2. ${ }^{13} \mathrm{C}$ NMR spectrum (typical ester and ether regions) of a representative PLLA- $b$-PEO- $b$-PLLA triblock copolymer synthesized by sequential ROP of EO and LLA via the base-to-base organocatalytic approach (EO2LLA1 in Table 1). 

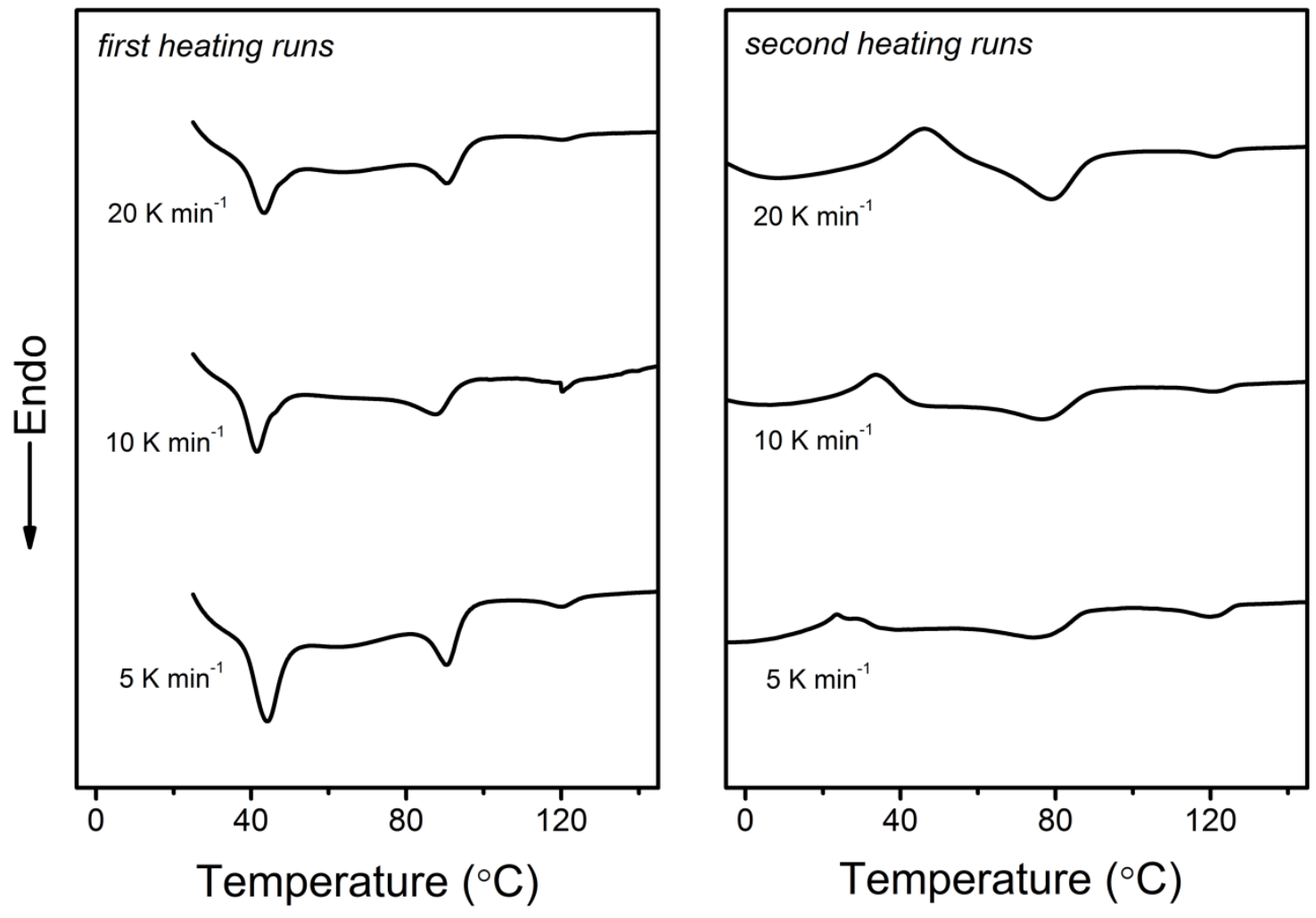

Figure S3. DSC traces of first (left) and second (right) heating runs at different heating rates of a PLLA$b$-PEO-b-PLLA triblock copolymer with relatively longer PLLA blocks synthesized by the base-to-base organocatalytic approach as depicted in Figure S4.

Three different heating/cooling rates are applied in the DSC analysis for this sample. Melting peaks for both PEO and PLLA are observed in the first heating run (left figure). However, crystallization peaks are not shown in the cooling runs regardless of the cooling rates, indicating that the crystallization of this triblock copolymer is quite a slow process. Cold crystallization processes are observed in the second heating runs as presented in the right figure, which are followed by two melting peaks centered, respectively, at ca. $78{ }^{\circ} \mathrm{C}$ and $122{ }^{\circ} \mathrm{C}$. The first melting peak may derive from the restricted crystallization of PLLA segments near the central PEO block due to the good miscibility in their amorphous state. ${ }^{1}$ The second heating peak can be attributed to the less influenced crystallization of PLLA segments (near the terminals) which are away from the central PEO block. Detailed analysis and discussion on the crystallinity is out of the scope of the present study. 


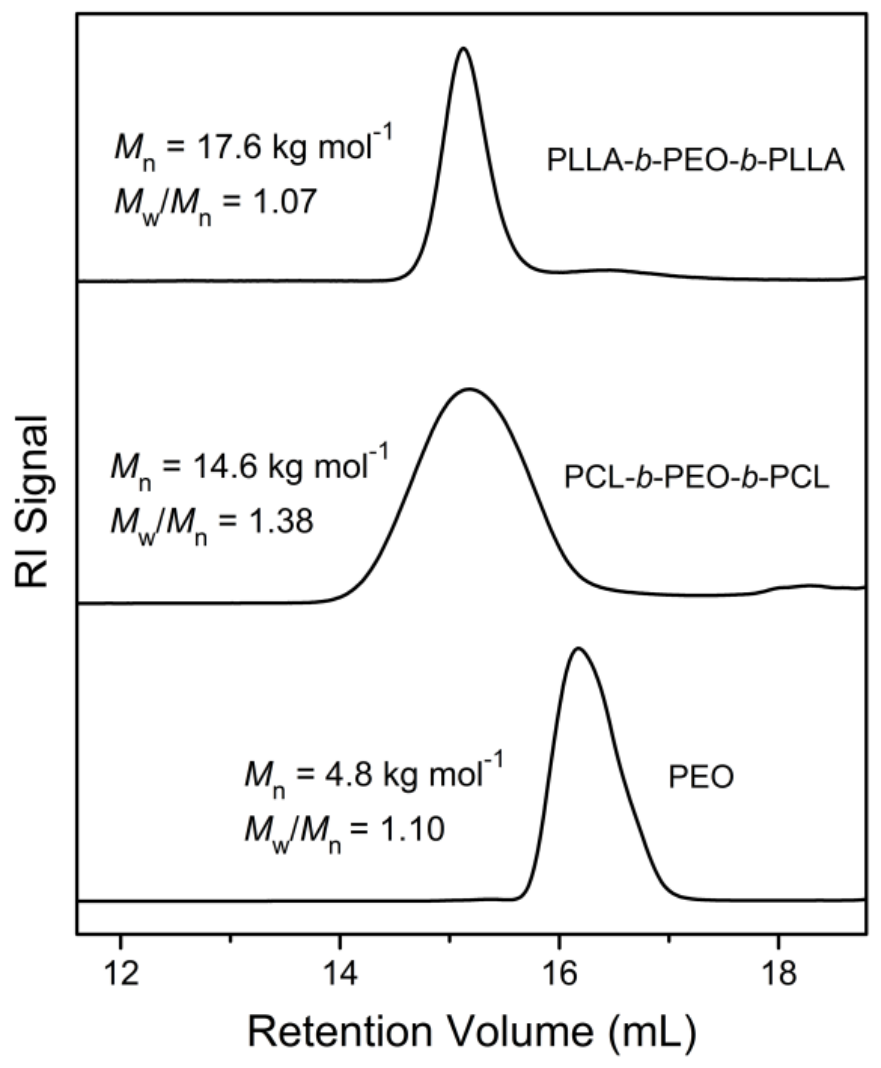

Figure S4. SEC traces (THF, $35^{\circ} \mathrm{C}$, PEO standards) of a PEO precursor, PCL- $b$-PEO- $b$-PCL and PLLA$b$-PEO- $b$-PLLA triblock copolymers derived from it (not listed in Table 1) via the base-to-base organocatalytic approach with the initial ratio of $\left[t-\mathrm{BuP}_{4}\right]_{0} /[\mathrm{OH}]_{0}$ being 0.2 and DTU1 as the second catalyst $\left([\mathrm{TU} 1]_{0} /\left[\mathrm{O}^{-}\right]_{0}=0.12\right)$; reaction time of $\mathrm{CL} / \mathrm{LLA}=1 \mathrm{~h}$. 

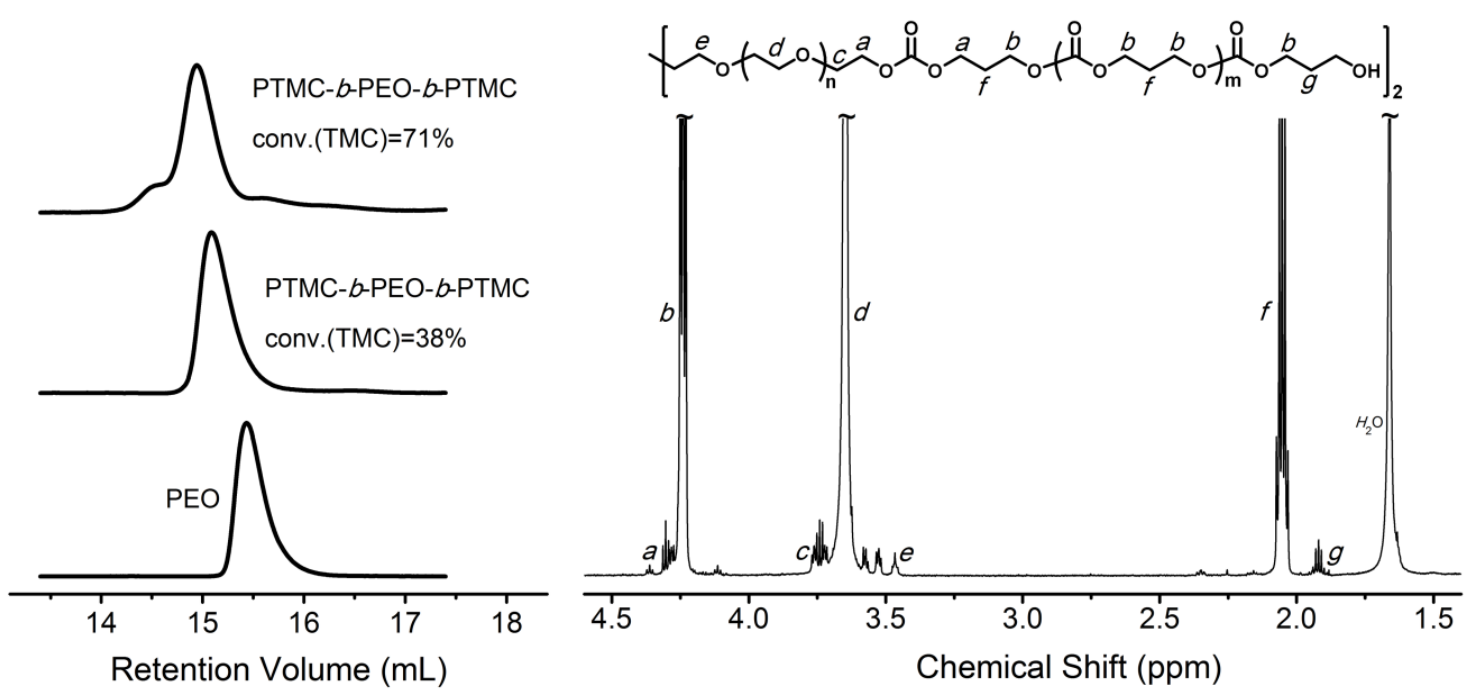

Figure S5. SEC traces (left, RI signal in THF, $35^{\circ} \mathrm{C}$ ) of PEO precursor and PTMC- $b$-PEO- $b$-PTMC triblock copolymers synthesized by sequential ROP of EO and TMC via the base-to-base organocatalytic approach (EO3TMC3 and EO3TMC2 in Table 1) and the ${ }^{1} \mathrm{H}$ NMR spectrum of isolated EO3TMC3 (right).

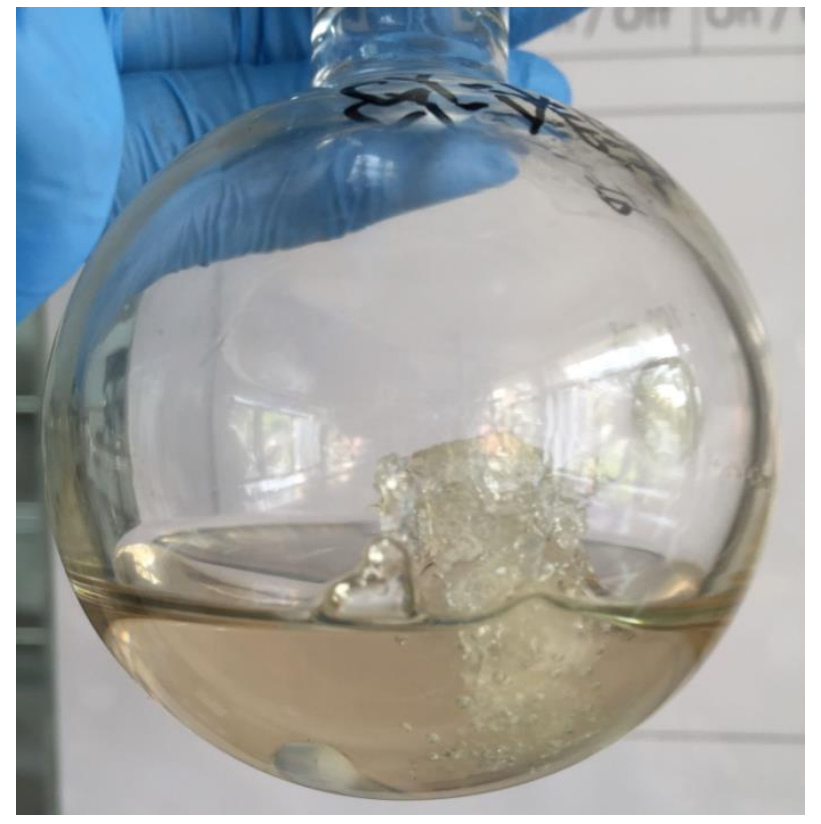

Figure S6. Photograph of the insoluble gel-like product yielded upon addition of IPDI to the solution of "living" PEO after the $t$-BuP 4 -catalysed ROP of EO without "catalyst switch", which stays as it is in the photograph (no sign of dissolution) upon waiting for a couple of days. 

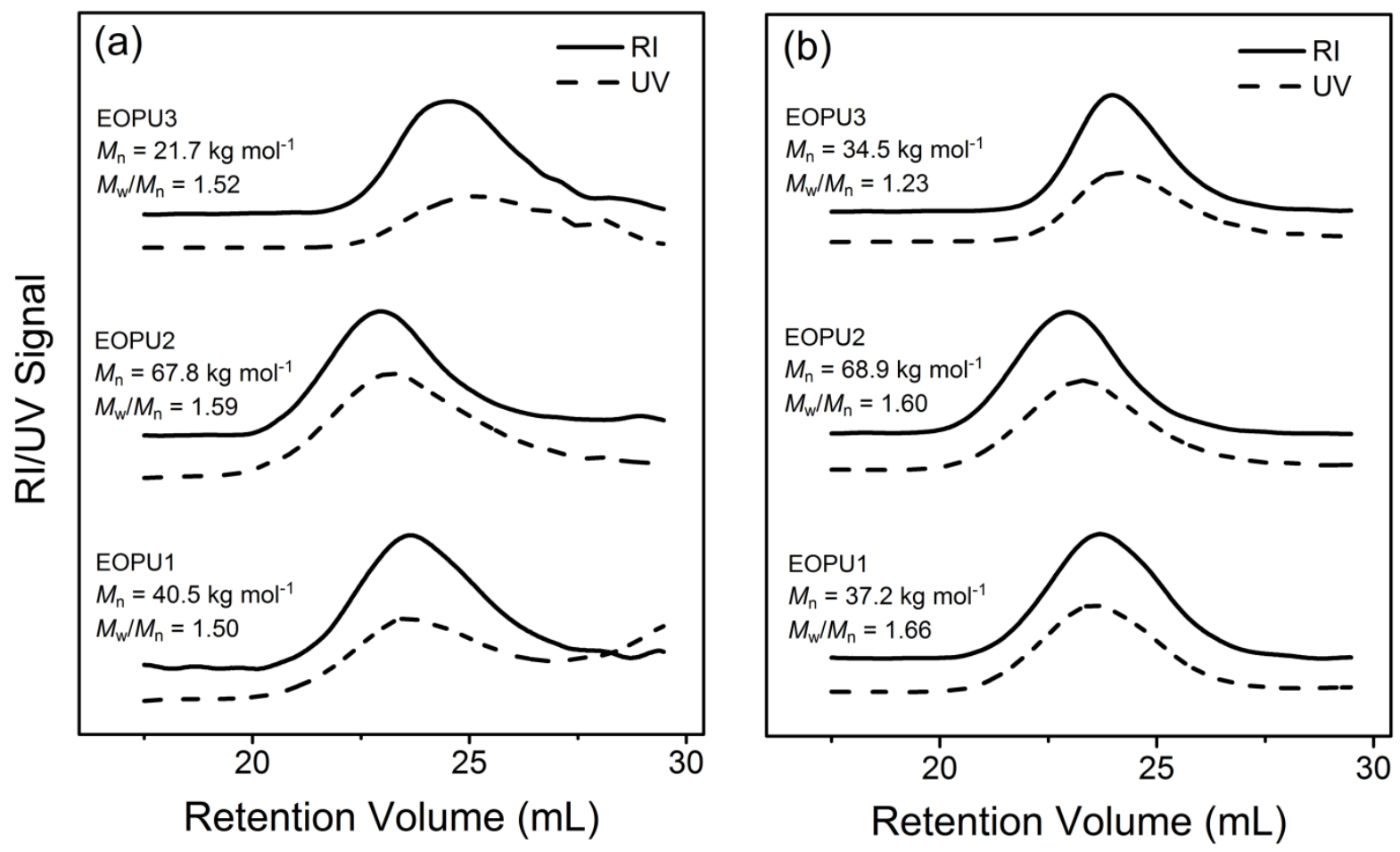

Figure S7. SEC traces (DMF, $50{ }^{\circ} \mathrm{C}$, PEO standards) of the PEO-PUs synthesized by sequentially performed ROP and SGP via the base-to-base organocatalytic approach before (a) and after precipitation (b). SGP for EOPU1 and EOPU2 was carried out at $30{ }^{\circ} \mathrm{C}$ for $72 \mathrm{~h}$ and SGP for EOPU3 was carried out first at $30{ }^{\circ} \mathrm{C}$ for $120 \mathrm{~h}$ then at $50{ }^{\circ} \mathrm{C}$ for another $48 \mathrm{~h}$ (Table 2).

\section{Reference}

(1) Castillo, R. V.; Müller, A. J. Crystallization and Morphology of Biodegradable or Biostable Single and Double Crystalline Block Copolymers. Progr. Polym. Sci. 2009, 34, 516-560. 